\title{
Health Associated with Several Common Exercises and Different Intensities of Exercises
}

\author{
Weibiao Du \\ School of North China Electric Power University, Baoding 071000, China \\ 1019425754@qq.com
}

\begin{abstract}
Exercises can enhance health index. Through exercising, people's physical and psychological health can both be reached, and his/her inner quality is also burnished. Cycling promotes blood circulation, reduces body weight and releases negative emotions. Football playing trains leg bones and improves the function of the respiratory system. Meanwhile, its life-prolonging and disease-preventing effect are much accounted of. Badminton-playing improves one's explosiveness, agility and coordination. To make the long essay short, choose the best type and intensity of exercises to benefit people's health.
\end{abstract}

Keywords: health, exercise, type, intensity.

\section{Introduction}

There is no doubt that health has a very close connection with exercises. When exercising, our blood is circulated faster in the vessels, our muscles are strengthened and our mind can be cleared. Therefore, one may have a healthy and happy life with these wally physical and psycological conditions. With some exercises you may have already heard a thousand times, for example, cycling, football, badminton, boxing, ping-pong, basketball, a man can invigorate health effectively and burnish his character. Agility, endurance, tenacity, share, teamwork and so on can be obtained in the sports. However, it doesn't mean that the more one exercise, the healthier he/she could be. Moderate exercises are also put into principle. That's the foundation of people's long-life-span and protection from diseases.

\section{Several types of exercise}

Several common exercises like cycling, football will not only exercise one's body, but also add positive ingredients in the mind during the process. In the mean time, his or her inner quality is exercised, too.

\subsection{Cycling}

With the popularity of environmental protection and body-health-caring concept, cycling becomes a fashion in the world. Behind the fashion is the sound effect to prevent heart diseases. You can not image that more than half of people die from heart diseases every year. When a person ages, his or her blood vessels would get slim and residual would harden the arteries, which hinders fresh blood from bumping around the whole body. Then, one will feel fatigue frequently and, going a step further, be more susceptible to various heart diseases. Riding bikes is a commendable way to prevent or even cure of that. In medicine, Collateral Circulation [1] is an important concept. Biking helps to pump the blood around all parts of body as well as draw back some used blood from nerve endings through the movement of legs. That can surely strengthen microvasculars. It is not until the blood vessels are strengthened that the body can stay young. According to statistics, a person weighing $75 \mathrm{~kg}$, riding 73 miles, with the speed of nine and a half miles per hour, can reduce half a kilogram of body weight, but he/she must persevere with it every day.[2] In addition, cycling can clear one's mind and contribute to a pleasant mood. Brain intakes more oxygen through the speeded blood. After riding for a while, one will feel more clearly in mind. He or she will feel free all over the body. It is not just a kind of movement of reducing weight, but also the release of feelings. 


\subsection{Football}

When you watch the World Cup of Brazil in 2014, you must be addicted to the ball flying here and there and you are captivated by the players' superb skills. However, do you reflect on the advantages of football playing itself? First of all, it's one of the best sports to train leg bones. In the process of constant movement of the legs, due to promotion of metabolism, bone blood supply is ameliorated and bone structure and function are improved. Moreover, football playing is also an effective way to improve the function of the respiratory system. In running, passing and shooting, oxygen and carbon dioxide exchanging increases lung capacity and strengthens lung function. The main well group and the auxiliary breathing muscle group have powerful contraction to breathe, and, at the same time, they develop themselves. Study has pointed out that the person who often plays football has a smooth and dark breath, and the frequency is also lower. His or her breathing rate is 7 to 11 times per minute but for those, who do not exercise or exercise a little, the breath frequency rate is 12 to 18 times per minute.[3] One benefit for health from the men's sports is the life-prolonging and disease- preventing effect. With a decade's research, scientists have discovered that people who do not exercise have a 42.5\% larger possibility to become premature death. The reason is that the body not exercised will accelerate aging in various places, and even get prematurely senile. And these people, who do not often exercise, also have a lower resistance against cancer and heart disease. Accordingly, playing football is not just men's sports, yet the entire humankind's sports.

\subsection{Badminton}

Badminton is the fastest in all sports, much quicker than F1 and Robles, Chen Wenhong from Malaysia once beat a $421 \mathrm{~km} / \mathrm{h}$ speed. Famous Chinese badminton player Lin Dan once said. With so high speed, one must have enough explosiveness to beat the ball and the other have enough agility to bounce it back. In an exercise or a game, one has to swing the racket several hundred times. Its intensity is roughly equal to several dozens of lifting, though you may not realize it. So muscles in his/her arms can be strengthened vastly. However, it's not only the arms are strengthened, but the whole body, in other words, the coordination. Before the successful hit, badminton player has to focus the eyes on the ball, lower his barycenter, lean back and start the fatal blow. In just one hit, the player's eyes, brain, hands, feet, shoulders, waist, arms and legs are combined together unconsciously. Another advantage of badminton-playing lies in the perspective of safety. There is rarely body conflict between two players, which avoids being hurt and injured. In this view, badminton is better than football and basketball. So, badminton is good for almost everybody, no matter you are young or old, man or woman.

\section{Suggestions}

Health can be benefited from these common exercises. However, there are also some different intensities to choose. Not all people will choose boxing as a hobby or a regular, for everybody has different body constitutions. If you want a man with weak body condition to do the intense exercise, he may often get injured easily; if you make a man with good body constitution do little mild exercise, he may not get exercised. Besides that, though one finally chooses right kinds of sports, it also matters how much he or she plays it.

\section{Conclusion}

In the world, there are thousands of kinds of exercises and there are thousands of kinds of people. Each person can choose several exercises to strengthen his/her body constitution and enhance his/her health index. So don't be lazy in bed or busy in office, just go to the gym, outdoors or other places that one can exercise. But one point must be valued, that is amount.

Everybody has different situations. Thus, acquaintance the exercise and acquaintance yourself. Choose the best type and intensity of exercise to benefit your health. 


\section{Acknowledgements}

At the very moment of finishing this paper, I'd like to express my gratitude to my lovely and beautiful supervisor, Ms.Gu. Ms.Gu helped me in material researching, material arranging and thesis format writing. Without her selfless devotion, I can't complete this essay. In addition, I would like to express my thanks to the authors of books which provided me with a lot of reliable facts and data. And I'm also grateful to some e-books, which helped me greatly in materials.

\section{References}

[1] http://baike.so.com/doc/6425781.html

[2] http://wenda.so.com/q/1362517886066401

[3] http://wenda.so.com/q/1367379396061749?src=150 